\title{
Synthesis of High Surface Area Mesoporous Silica Powder Using Anionic Surfactant
}

\author{
Sang-wook Ui, In-seok Choi, and Sung-churl Choi \\ Division of Materials Science \& Engineering, College of Engineering, Hanyang University, 17 Haengdang-dong, Seongdong-ku, \\ Seoul 133-791, Republic of Korea \\ Correspondence should be addressed to Sung-churl Choi; choi0505@hanyang.ac.kr
}

Received 5 November 2013; Accepted 11 December 2013; Published 5 February 2014

Academic Editors: J. L. C. Fonseca and Y. Yue

Copyright (C) 2014 Sang-wook Ui et al. This is an open access article distributed under the Creative Commons Attribution License, which permits unrestricted use, distribution, and reproduction in any medium, provided the original work is properly cited.

\begin{abstract}
Over the past several years, synthesized mesoporous nanosilica $\left(\mathrm{SiO}_{2}\right)$ powders have been developed by many different methods. The methods include precipitation and microemulsion, the Stöber method, chemistry, and technology. In this study, mesoporous silica powders are synthesized by the sol-gel method. The sol-gel method obtains a high purity silica powder; however, the process yields a low percentage. Past syntheses of $\mathrm{SiO}_{2}$ powder precursors are expensive, but this study needs to find a replacement precursor for low cost alternatives. A high surface area was used to form an anion surfactant sodium dodecyl sulfate, which regulates the molar concentration. The particles size variability was changed by the precursor molar ratio of the sodium silicate solution with hydrochloric acid.
\end{abstract}

\section{Introduction}

The silica powders are considered competent materials because of their unique characteristics, such as low density, low thermal conductivity, high surface area, high thermal shock resistance, and high specific strength $[1,2]$. They also have the potential to be used in a wide range of applications, including catalysts, thermal and electrical insulators, adsorbents, filters, light-weight structural materials, optoelectronic devices, humidity sensors, chemical polishing, and other fine precision equipments [3-6]. According to recent academic and technical reports, various chemical methods have been developed to control the particle shapes, size, and distribution of fine silica particles. In the conventional method, ammoniacatalyzed reactions of tetraethylorthosilicate with water in low-molecular-weight alcohols are synthesized by Stöber method. However, this method has to use a high cost alkoxide or organometallic compound. In this work, we demonstrate a sol-gel method that controls the sphere size, cubic shapes, and mesoporous silica using the low cost sodium silicate solution with surfactant sodium dodecyl sulfate (SDS). The pore size and surface area of the silica varied with $\mathrm{pH}$ and aging time.
The characteristics of the silica varied with the change in surface area, pore volume, and particle shapes.

\section{Experimental}

2.1. Synthesis. The flow chart in Figure 1 shows the experimental steps involved in the rapid processing of cubic silica powders. In a study on the typical synthesis, the water glass solution was prepared in a beaker and the $1 \mathrm{M} \mathrm{HCl}$ solution dripped for 30 minutes. The mixture was stirred for 10 hours with a magnetic bar at $400 \mathrm{rpm}$ using a churner [7]. The water glass solution was diluted with the desired weight percentage of silica in the starting material then washed in running water using a filter paper. In the washing process, our group used at least $5 \mathrm{~L}$ of deionized water to remove $\mathrm{Na}^{+}$ions from the water glass solution, resulting in the formation of silicic acid and got a high purity silica powder. [8] In the next step, the displaced pore water was then removed from the beaker and the organic-gels were dried at ambient pressure in hot air drying equipment at $80^{\circ} \mathrm{C}$. This far explained the fundamental synthesis of silica powder. Figure 2 shows the second method of the high surface area of nanoparticle silica. 


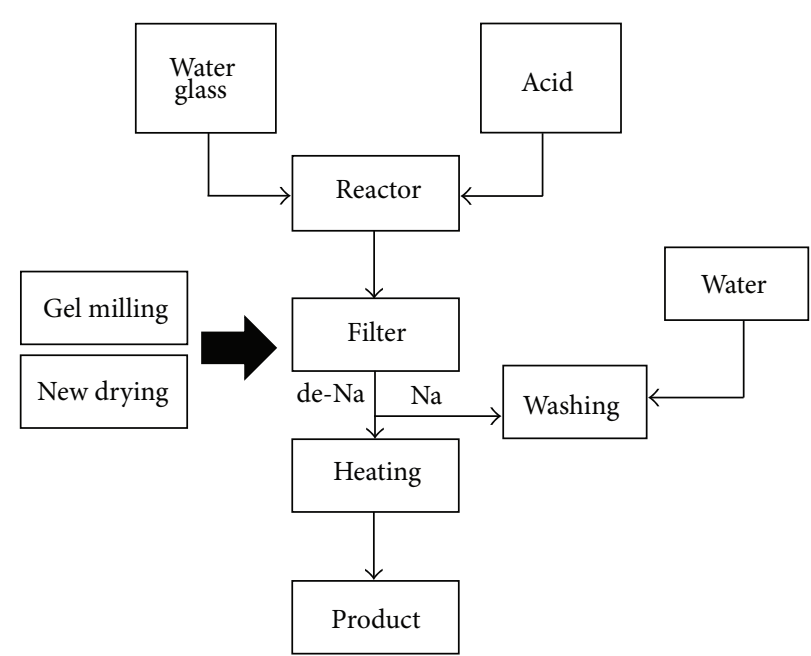

FIGURE 1: Flow chart showing the processing steps for the cubic silica powder.

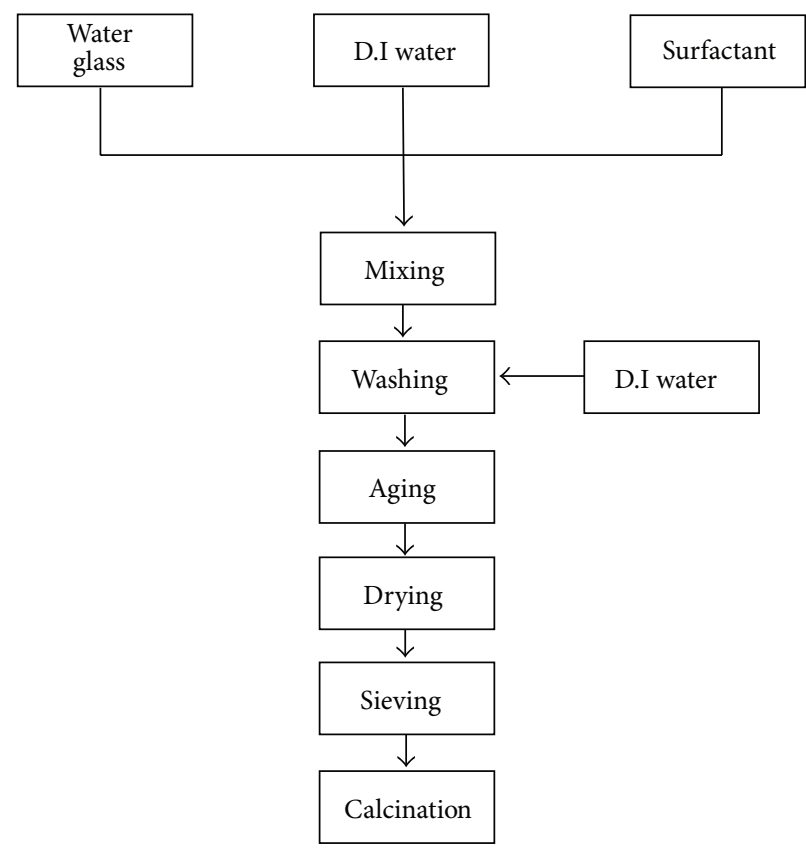

FIGURE 2: Flow chart showing the processing steps for high specific surface area of nanosilica power and spherical shape particles.

The high surface area silica powder manufactured for the experimental methods was based on experimental methods used for $\mathrm{pH}$ adjustment and surfactant. The reaction mixtures for the synthesis of high surface silica powder were prepared in beakers. pH 1 to 6 solutions were prepared by adding deionized water dropwise by a pipet. The other synthesis was performed with different proportions of reagents, surfactants, and $\mathrm{pH}$, which are summarized in Table 1. Sodium dodecyl sulfate (SDS) was dissolved by stirring in a mixture of deionized water and concentrated hydrochloric acid $(\mathrm{HCl})$. The stirring was stopped when the mixture was homogenized. The mixture was aged at $50^{\circ} \mathrm{C}$ in hot air drying equipment under static conditions for 24 hours. Precipitated gelation was filtered off, washed with $5 \mathrm{~L}$ deionized water, and dried at
TABLE 1: pH reaction condition ( $\mathrm{pH}$ 1 pH 6).

\begin{tabular}{lccccc}
\hline Number & WG & SDS & Water & HCI & $\mathrm{pH}$ \\
\hline 1 & 1 & 0.03 & 20 & 0.2 & 1 \\
2 & 1 & 0.03 & 20 & 0.2 & 2 \\
3 & 1 & 0.03 & 20 & 0.2 & 3 \\
4 & 1 & 0.03 & 20 & 0.2 & 4 \\
5 & 1 & 0.03 & 20 & 0.2 & 5 \\
6 & 1 & 0.03 & 20 & 0.2 & 6 \\
\hline
\end{tabular}

$80^{\circ} \mathrm{C}$ for 10 hours. The surfactant was removed by calcination at $700^{\circ} \mathrm{C}$ for 10 hours [9]. 


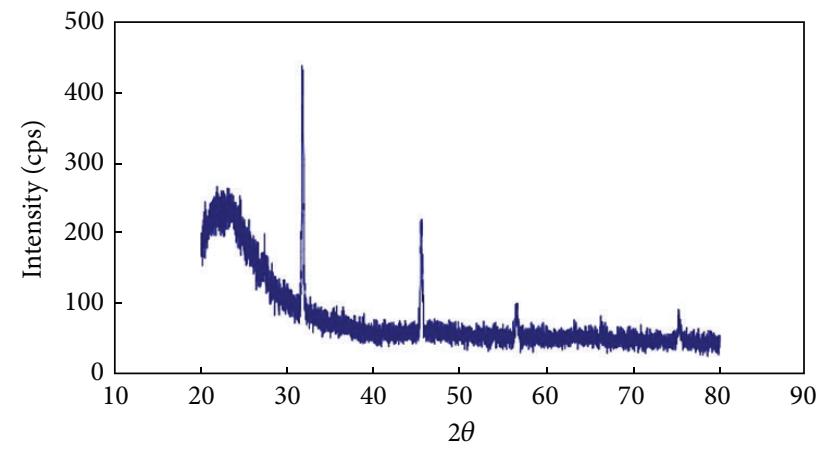

(a)

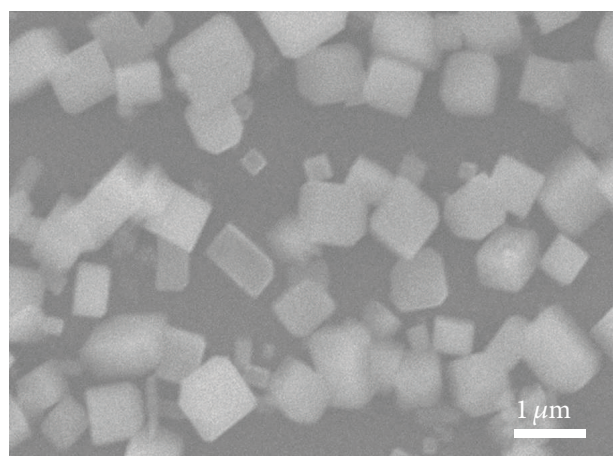

(b)

FIGURE 3: Centrifuges, hot air drying machine, XRD graph, and SEM image.

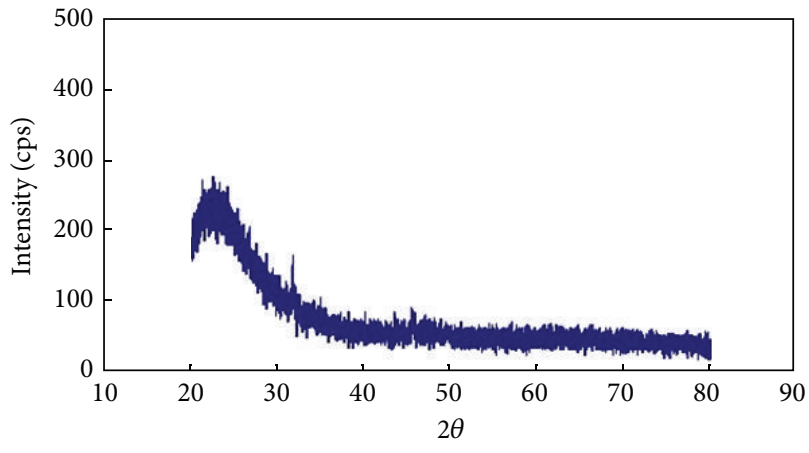

(a)

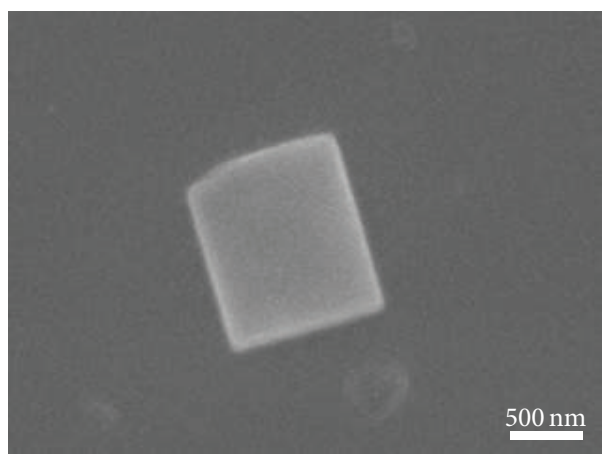

(b)

FIgURE 4: Filter paper washed and hot air drying machine.

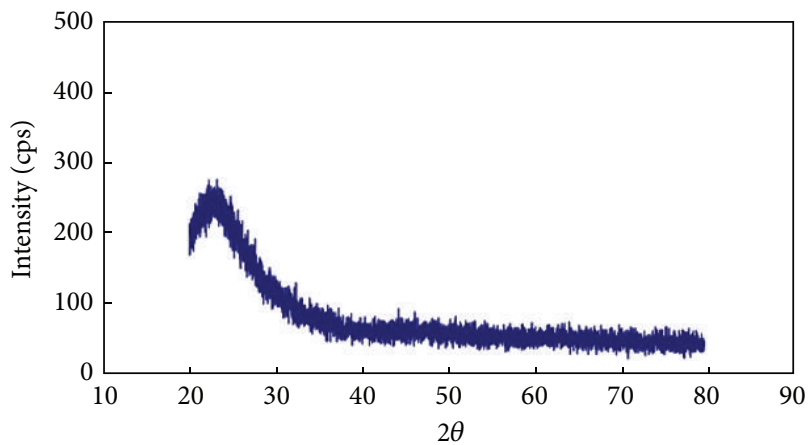

(a)

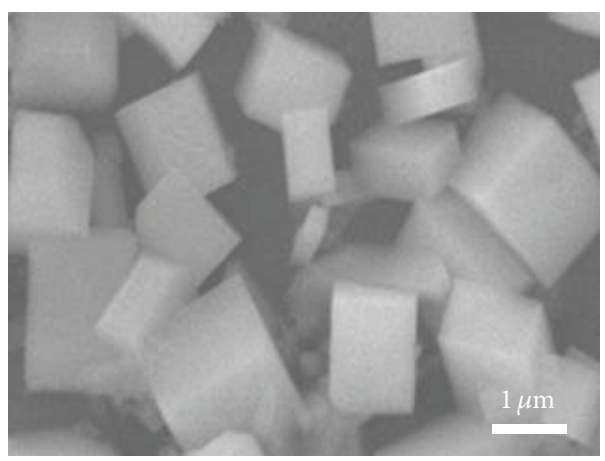

(b)

FIGURE 5: Filter paper and drying using a microwave.

2.2. Characterization. Field emission scanning electron microscopy (FE-SEM) was performed with a JEOL 6700F instrument to observe the particle morphology and size. Samples were gold-coated for SEM using a PS-2 coating unit. The crystal structure of the silica powder was determined by X-ray diffraction (XRD; Cu target; K $\alpha$; Philips DY616) and the operation parameters were scanned in a range of $2 \theta=$ $20-80^{\circ}$ and $40 \mathrm{kV}$. The surfactant effect of the silica powders was investigated by analyzing the surface area properties with standard $\mathrm{N}_{2}$ gas adsorption using a surface area analyzer. The silica powders were first degassed at $250^{\circ} \mathrm{C}$ for 3 hours and the adsorption/desorption of the liquid nitrogen was 


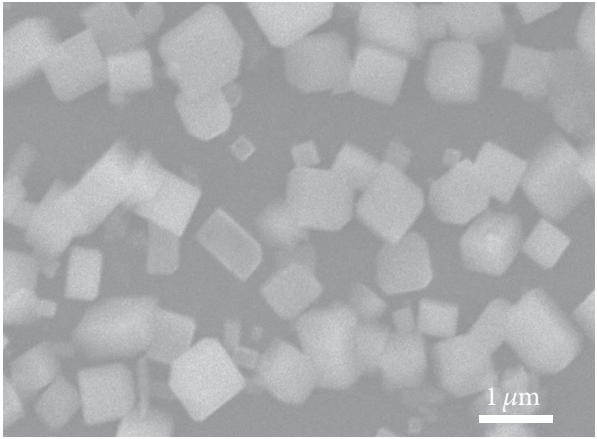

(a)

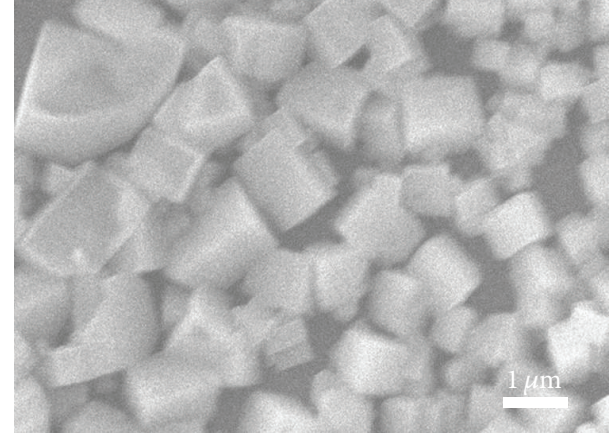

(b)

FIGURE 6: SEM image of cubic particles.

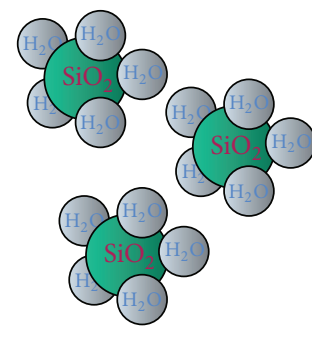

In solution
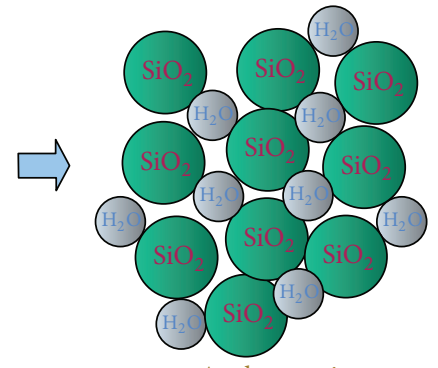

Agglomeration

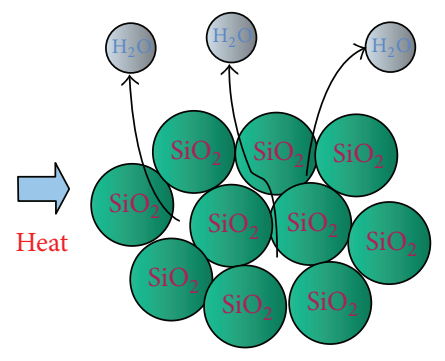

FIGURE 7: Increasing agglomeration of particle size in reverse proportion.

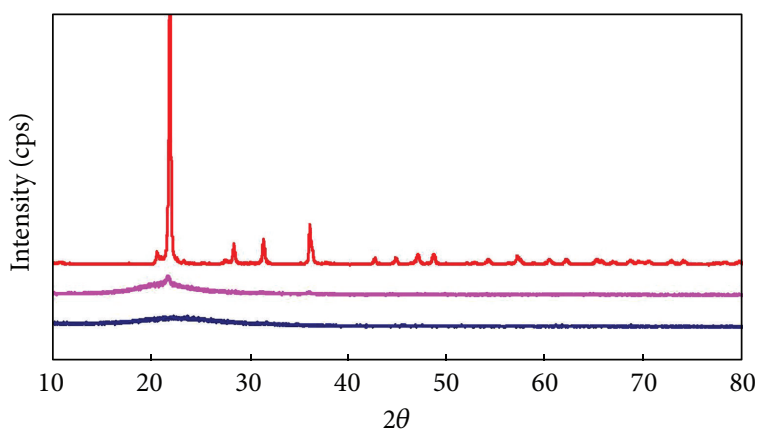

Figure 8: Effect of calcination.

recorded using equilibration times at approximately $5 \mathrm{~min}$ per point [10]. The specific surface area of the nanosilica powder was calculated by the Brunauer-Emmett-Teller (BET) method.

\section{Results and Discussion}

The basic chemical reactions of silica powder synthesis using a sodium silicate silica composite are

$$
\begin{gathered}
\mathrm{Na}_{2} \mathrm{SiO}_{3}+\mathrm{H}_{2} \mathrm{O}+2 \mathrm{HCl} \longrightarrow \mathrm{Si}(\mathrm{OH})_{4}+2 \mathrm{NaCl} \\
\mathrm{Na}_{2} \mathrm{SiO}_{3}+\mathrm{H}_{2} \mathrm{O}+\mathrm{H}_{2} \mathrm{SO}_{4} \longrightarrow \mathrm{Si}(\mathrm{OH})_{4}+\mathrm{Na}_{2} \mathrm{SO}_{4} \\
\mathrm{Si}\left(\mathrm{OCH}_{2} \mathrm{CH}_{3}\right)_{4}+\mathrm{H}_{2} \mathrm{O} \longrightarrow \mathrm{Si}(\mathrm{OH})_{4}+4 \mathrm{CH}_{3} \mathrm{CH}_{2} \mathrm{OH}
\end{gathered}
$$

High $\mathrm{pH}$ range (alkaline):

$$
\mathrm{Si}(\mathrm{OH})_{4}+\mathrm{OH}^{-} \longrightarrow \mathrm{Si}(\mathrm{OH})_{3} \mathrm{O}^{-}+\mathrm{H}_{2} \mathrm{O}
$$

Low $\mathrm{pH}$ range (acidic):

$$
\mathrm{Si}(\mathrm{OH})_{4}+\mathrm{H}_{3} \mathrm{O}^{+} \longrightarrow \mathrm{Si}(\mathrm{OH})_{3} \mathrm{OH}_{2}^{+}+\mathrm{H}_{2} \mathrm{O}
$$

Polymerization:

$$
\mathrm{Si}(\mathrm{OH})_{3} \mathrm{O}^{-}+\mathrm{Si}(\mathrm{OH})_{3} \mathrm{O}^{-} \longrightarrow \mathrm{Si}(\mathrm{OH})_{3}-\mathrm{O}-\mathrm{Si}(\mathrm{OH})_{2} \mathrm{O}^{-}+\mathrm{OH}^{-}
$$

For the synthesis of the silica powder, the remaining $\mathrm{Na}^{+}$ in sodium silicate was removed using sodium silica in the solgel process. [11, 12] In the silica sol, the $\mathrm{Na}^{+}$ion was breaking the silica network structures as a modifier during silica solgel gelation and decreasing the purity of silica powders. To remove the sodium from sodium silicate, sodium silicate was diluted to $10 \mathrm{wt} \% \mathrm{HCl}$ acid. Silica hydrogel was made by the sol-gel reaction after the sodium ions were removed by washing and the sodium crystallization was precipitated by centrifugation. $[13,14]$ There are two washing methods: deionized water washed on filter paper and a centrifugation method. Compared to the XRD data, the filter paper was better for removal of $\mathrm{Na}^{+}$ions to produce a more highpurity silica powder product; however, the main drawback is the loss of silica. [15-17] The shape of the cubic powder silica was synthesized with $1 \mathrm{M} \mathrm{HCl} 200 \mathrm{~mL}$ in the water glass solution by sol-gel. The silica powder product from each of 

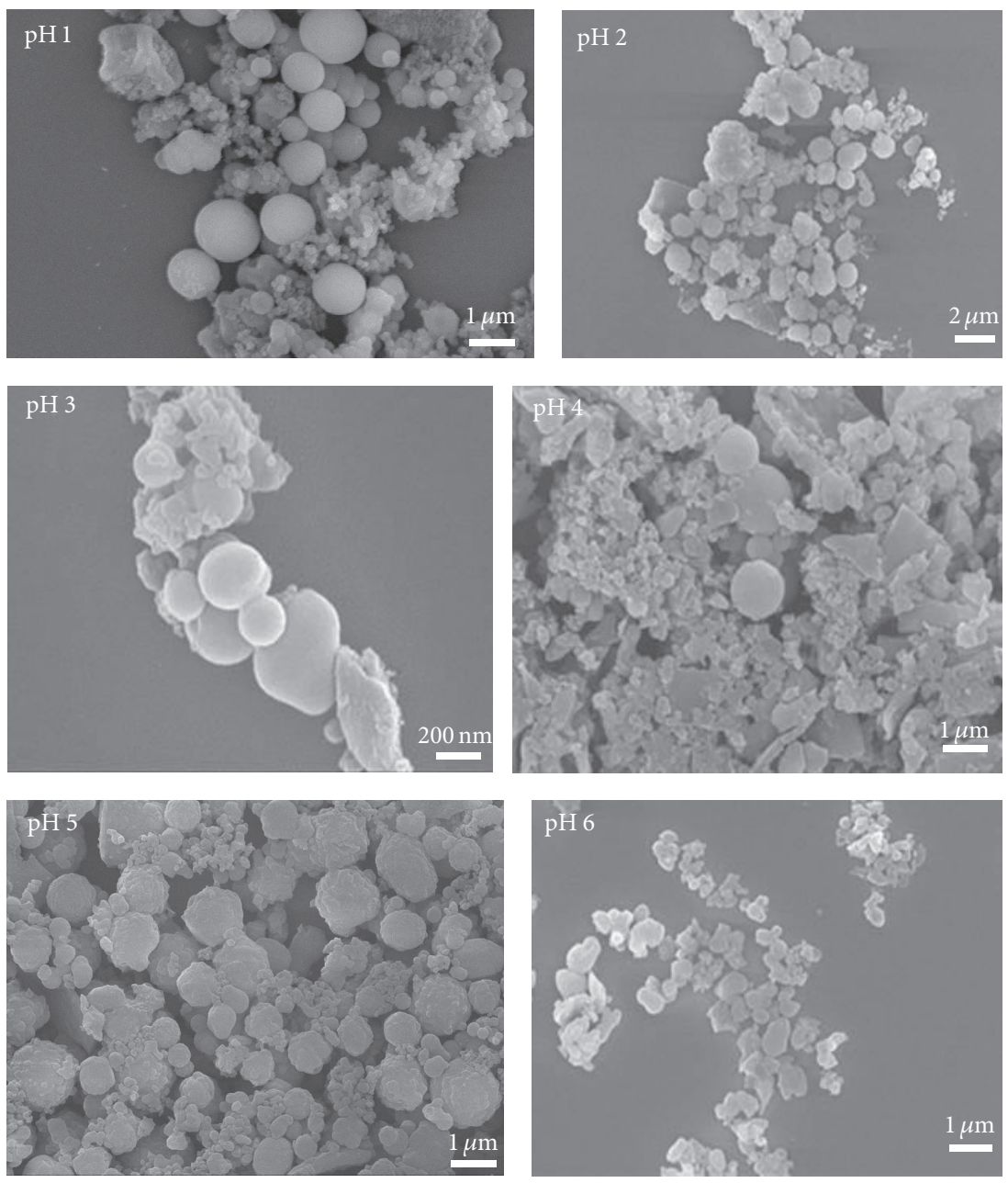

FIGURE 9: pH effect of particles shapes.

the washing and drying methods were confirmed by XRD and the morphology of the particles was examined using scanning electron microscopy (SEM) that is shown in Figures 3, 4, and 5.

In Figure 6, the SEM images of each particle confirm the cubic was approximately $500 \mathrm{~nm}$ to $1 \mu \mathrm{m}$ in diameter. Microwave drying could produce more aggregation than that shown in Figure 7, increasing the particle size in reverse proportion to the specific surface area that was smaller than the BET data and could not be confirmed. As shown in the XRD data results (Figure 8), the transition to full cristobalite occurred at $1200^{\circ} \mathrm{C}$. The $\mathrm{pH}$ change of the silica composite with reference to Figure 9 was performed. Figure 9 shows the change in the $\mathrm{pH} 1$ to 6 ranges of various particle morphology images observed by SEM. Lower $\mathrm{pH}$ values produced particle shapes with more spherical shapes; however, the BET specific surface area data of the particles did not differ with the $\mathrm{pH}$ change (Table 2).

\section{Conclusions}

The nanostructured silica powder particles were obtained over a range of $500 \mathrm{~nm}$ to $1 \mu \mathrm{m}$ particle sizes, with high
TABLE 2: Effect of $\mathrm{pH}$ specific surface area $\left(\mathrm{m}^{2} / \mathrm{g}\right)$.

\begin{tabular}{lc}
\hline $\mathrm{pH}$ & Specific surface area $\left(\mathrm{m}^{2} / \mathrm{g}\right)$ \\
\hline 1 & 857.84 \\
2 & 1403.24 \\
3 & 1370.02 \\
4 & 984.14 \\
5 & 630.10 \\
\hline
\end{tabular}

specific surface area and cubic and spherical shapes by changing the surfactant $\mathrm{pH}$ and drying methods with solgel process. The silica powders were characterized in terms of the silica content, specific surface area, particle size, particle shape, and pore size distribution. The synthesis of a $10 \%$ water glass solution with $1 \mathrm{M} \mathrm{HCl}$ created a mixture reaction that effectively produced cubic particles. Increasing deionized water and $\mathrm{HCl}$ molar ratios created smaller size particles. The obtained silica nanoparticle showed high specific surface area. 


\section{Conflict of Interests}

The authors declare that they have no conflict of interests.

\section{References}

[1] S. Smitha, P. Shajesh, P. Mukundan, T. D. R. Nair, and K. G. K. Warrier, "Synthesis of biocompatible hydrophobic silica-gelatin nano-hybrid by sol-gel process," Colloids and Surfaces B, vol. 55, no. 1, pp. 38-43, 2007.

[2] N. N. Ghosh and P. Pramanik, "Synthesis of nano-sized ceramic powders using precipitated silica in aqueous sol-gel method," Nanostructured Materials, vol. 8, no. 8, pp. 1041-1045, 1997.

[3] P. W. J. G. Wijnen, T. P. M. Beelen, K. P. J. Rummens, H. C. P. L. Saeijs, and R. A. van Santen, "Silica gel from water glass: a SAXS study of the formation and ageing of fractal aggregates," Journal of Applied Crystallography, vol. 24, no. 5, pp. 759-764, 1991.

[4] A. Fouzri, R. Dorbez-Sridi, and M. Oumezzine, "Water confined in silica gel and in vycor glass at low and room temperature, x-ray diffraction study," Journal of Chemical Physics, vol. 116, no. 2, pp. 791-797, 2002.

[5] M. Helmich and F. Rauch, "On the mechanism of diffusion of water in silica glass," Glastechnische Berichte, vol. 66, no. 8, pp. 195-200, 1993.

[6] T. Matsuzawa, K. Mase, and S. Inoue, "Synthesis and application of a silica nanocomposite filler using water glass and a resoletype phenol resin," Journal of Applied Polymer Science, vol. 112, no. 6, pp. 3748-3753, 2009.

[7] A. Agarwal, M. Tomozawa, and W. A. Lanford, "Effect of stress on water diffusion in silica glass at various temperatures," Journal of Non-Crystalline Solids, vol. 167, no. 1-2, pp. 139-148, 1994.

[8] K. Aramaki, "Synergistic inhibition of zinc corrosion in 0.5 $\mathrm{M} \mathrm{NaCl}$ by combination of cerium(III) chloride and sodium silicate," Corrosion Science, vol. 44, no. 4, pp. 871-886, 2002.

[9] J. Yatabe, T. Yamada, T. Mogi, S. Yamada, T. Ikawa, and T. Kageyama, "Preparation of porous amorphous silica from water glass as raw materials," Nippon Kagaku Kaishi, vol. 3, 304 pages, 1993.

[10] J. Chandradass, S. Kang, and D.-S. Bae, "Synthesis of silica aerogel blanket by ambient drying method using water glass based precursor and glass wool modified by alumina sol," Journal of Non-Crystalline Solids, vol. 354, no. 34, pp. 4115-4119, 2008.

[11] Y. Arai, H. Segawa, and K. Yoshida, "Synthesis of nano silica particles for polishing prepared by sol-gel method," Journal of Sol-Gel Science and Technology, vol. 32, no. 1-3, pp. 79-83, 2004.

[12] A. Borisov, Y. Lahaye, and H. Palme, "The effect of sodium on the solubilities of metals in silicate melts," American Mineralogist, vol. 91, no. 5-6, pp. 762-771, 2006.

[13] K. M. Davis and M. Tomozawa, "Water diffusion into silica glass: structural changes in silica glass and their effect on water solubility and diffusivity," Journal of Non-Crystalline Solids, vol. 185, no. 3, pp. 203-220, 1995.

[14] M. Tomozawa, D.-L. Kim, and V. Lou, "Preparation of high purity, low water content fused silica glass," Journal of NonCrystalline Solids, vol. 296, no. 1-2, pp. 102-106, 2001.

[15] K. Kamiya, A. Oka, H. Nasu, and T. Hashimoto, "Comparative study of structure of silica gels from different sources," Journal of Sol-Gel Science and Technology, vol. 19, no. 1-3, pp. 495-499, 2000 .
[16] F. W. Chang, M. T. Tsay, M. S. Kuo, and C. M. Yang, "Characterization of nickel catalysts on $\mathrm{RHA}-\mathrm{Al}_{2} \mathrm{O}_{3}$ composite oxides prepared by ion exchange," Applied Catalysis A, vol. 226, no. 1-2, pp. 213-224, 2002.

[17] B. Andričić, T. Kovačić, and I. Klarić, "Kinetic analysis of the thermooxidative degradation of poly(vinyl-chloride) in poly(vinyl chloride)/methyl methacrylate-butadiene-styrene blends-2. Nonisothermal degradation," Polymer Degradation and Stability, vol. 79, no. 2, pp. 265-270, 2003. 

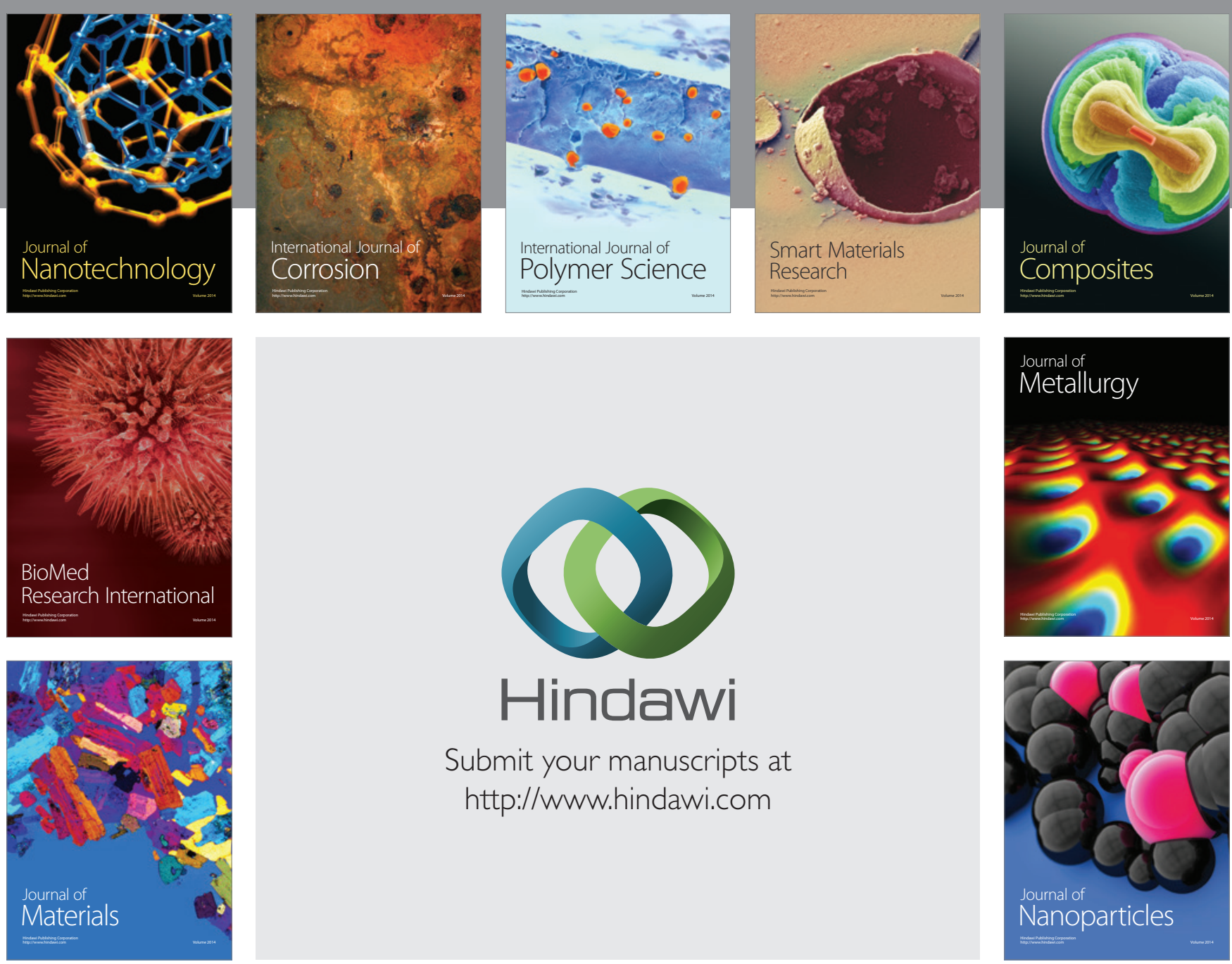

Submit your manuscripts at http://www.hindawi.com
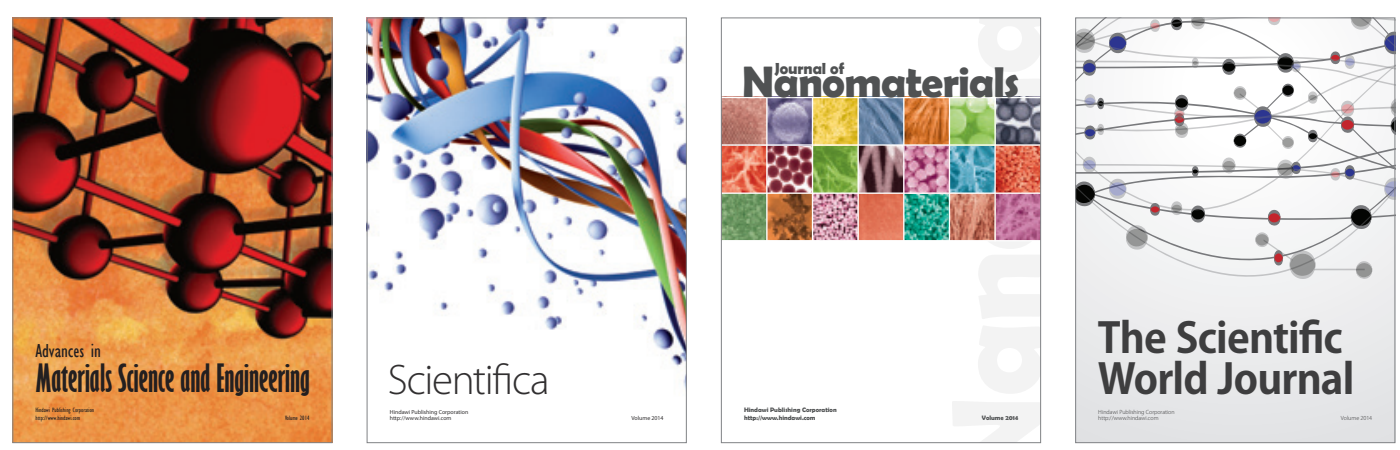

\section{The Scientific World Journal}
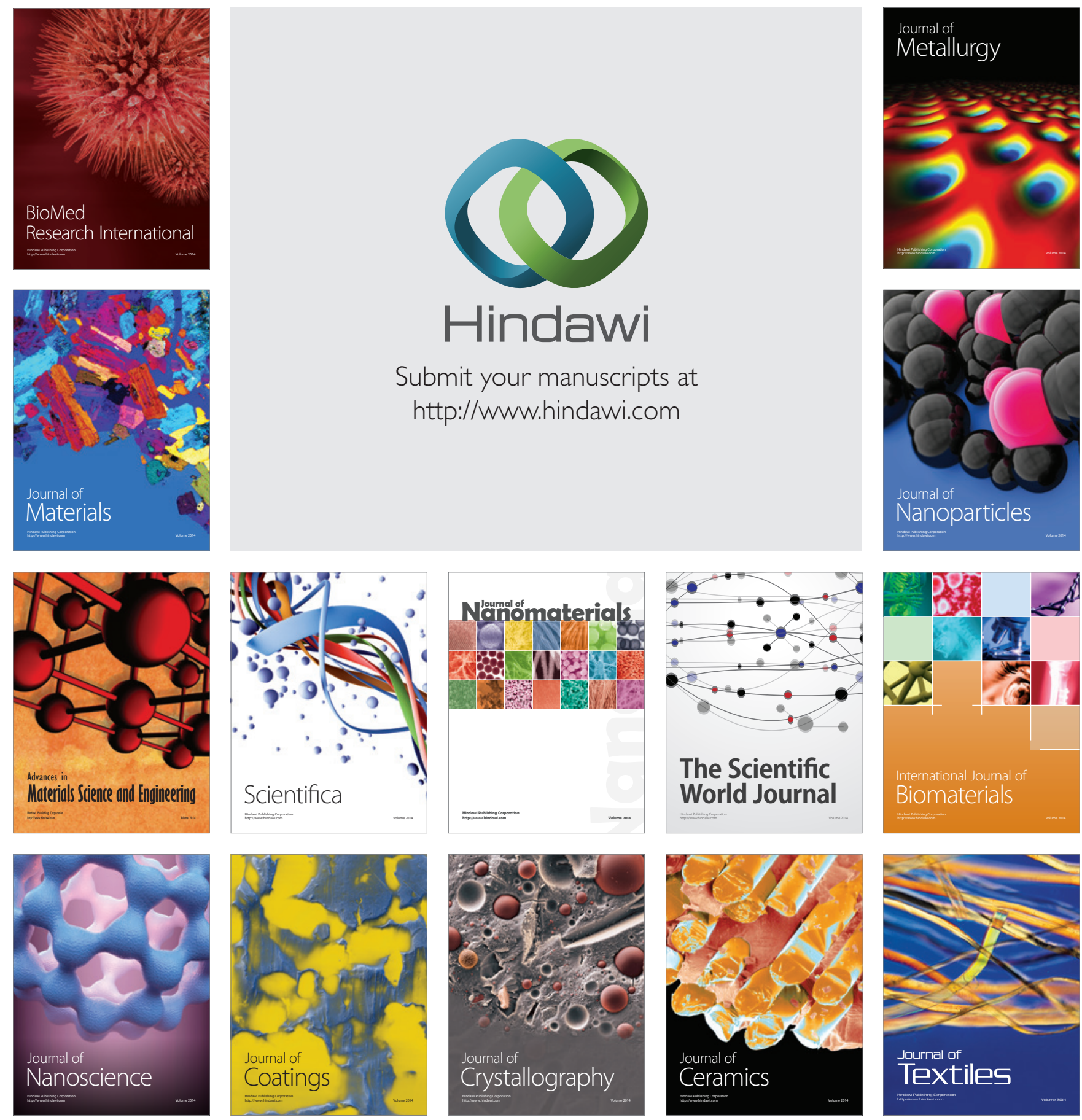